\title{
ULTRASTRUCTURAL LOCALIZATION OF SURFACE RECEPTORS FOR CONCANAVALIN A ON RABBIT SPERMATOZOA
}

\author{
MILDRED GORDON, P. V. DANDEKAR AND W. BARTOSZEWIGZ \\ Department of Obstetrics and Gynecology, Yale University School of Medicine, \\ New Haven, Connecticut, U.S.A.
}

(Received 26th Fuly 1973)

During penetration of the investments of the egg, the spermatozoon loses the outer acrosomal membrane and the corresponding portion of the plasma membrane permitting release of the acrosomal contents (Barros, Bedford, Franklin \& Austin, 1967; Yanagimachi \& Noda, 1970). This co-ordinated morphological change, the acrosome reaction, does not take place in non-capacitated spermatozoa (Austin, 1964). Because the behaviour of the plasmalemma of the capacitated sperm head is functionally differentiated from that of epididymal or ejaculated spermatozoa, several attempts have been made to demonstrate differences between the membranes of such spermatozoa. Fine structural analysis of the plasmalemma has so far yielded little information.

Recent investigations of the plasmalemmal surface coat during sperm maturation, capacitation and fertilization, have indicated removal of sperm-coating antigens by the uterine environment (Kirton \& Hafs, 1965; Hunter \& Nornes, 1969; Johnson \& Hunter, 1972). Because some of these antigens are glycoproteins, among them decapacitation factors (Dukelow, Chernoff \& Williams, 1967), their removal has been attributed to modification in the surface coat, particularly the carbohydrate moieties (Dukelow, Chernoff \& Williams, 1966). This conclusion is based on the observation that spermatozoa may be partly capacitated in vitro by enzymes digesting carbohydrates (Kirton \& Hafs, 1965; Hunter \& Nornes, 1969; Gwatkin \& Hutchison, 1971; Johnson \& Hunter, 1972).

Utilization of plant lectins for sperm agglutination (Nicolson \& Yanagimachi, 1972), localization of fluorescein-labelled plant agglutinins, and ${ }^{125} \mathrm{I}$ labelled plant agglutinins (Edelman \& Millette, 1971), have revealed receptors for Concanavalin A (Con A) on rabbit and mouse spermatozoa. Because Con A has been employed for the electron microscopic visualization of terminal oligosaccharide residues in cell-coats (Bernhard \& Avrameas, 1971), we adapted this method to demonstrate the distribution of Con A receptors on the surface of ejaculated and capacitated rabbit spermatozoa.

Ejaculates were centrifuged to remove seminal plasma, and the precipitated spermatozoa were resuspended in phosphate-buffered saline (PBS), pH 7.2. After washing, the centrifuged pellet was incubated in PBS containing $50 \mu \mathrm{g}$ Con $\mathrm{A} / \mathrm{ml}$ for $15 \mathrm{~min}$. After incubation, the cells were rinsed in PBS and 
incubated for $15 \mathrm{~min}$ in $20 \mu \mathrm{g}$ horseradish peroxidase/ml PBS. After a rinse in PBS, spermatozoa were placed in diaminobenzidine $(\mathrm{DAB})$ solution $(0.5 \mathrm{mg} / \mathrm{ml}$

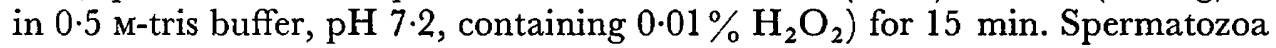
were then washed in PBS and fixed in $1.5 \%$ glutaraldehyde. Some samples were fixed in glutaraldehyde before, and some after, treatment with DAB. They were then placed in osmium tetroxide and processed for electron microscopy. Capacitated spermatozoa were flushed from the uterus with PBS $15 \mathrm{hr}$ after mating and were given identical treatment to that of ejaculated cells. In control preparations, spermatozoa were not exposed to Con A. Sections were examined in an Hitachi HU-12 electron microscope, either unstained or following light staining with uranyl acetate and lead citrate.

Examination of ejaculated spermatozoa revealed a dense layer of reaction product that uniformly covered the plasmalemma of the sperm head (Pl. 1, Fig. 2). The other membranes of the head showed no reaction (Pl. 1, Fig. 3). They also showed no reaction in cells where the acrosomal portion of the plasmalemma (which is more fragile than the rest of the cell membrane) was broken during incubation, permitting access of Con $\mathrm{A}$ to acrosomal and nuclear membranes. No striking differences could be discerned in deposition of reaction product on the acrosome, or postacrosomal cap (Pl. 1, Fig. 2), but over the flagellum the layer of reaction product was noticeably thinner (Pl. 1, Fig. 4) and some areas showed no surface localization. There was slight reduction of reaction product deposition in cells fixed before exposure to DAB, compared with those fixed after, but the differences were not marked. Most observations were carried out on spermatozoa fixed before such exposure. When incubation with Con A was omitted, there were no deposits on the cell surface (Pl. 1, Fig. 1).

In capacitated spermatozoa, the layer of reaction product was not as uniform over the head. In all the cells examined, the cephalic tip of the head was devoid of reaction product (Pl. 1, Fig. 6) revealing the unit membrane of the plasmalemma. The deposit over the area of the postacrosomal cap appeared to be more resistant to the forces affecting the surface layer. The reaction product on

\section{EXPLANATION OF PLATE I}

Fig. 1. Ejaculated rabbit spermatozoa incubated without exposure to Gon A. No deposit of reaction product is seen over the head (a) or flagellum (b). Stained with uranyl and lead salts. $\times 21,000$.

Fig. 2. Head of ejaculated rabbit spermatozoon incubated with Con A. Reaction product covers the entire membrane. There is no apparent difference in localization over the acrosome (arrow) or postacrosomal cap (pointer). Stained with uranyl and lead salts. $\times 21,000$.

FIG. 3. Anterior portion of head of ejaculated rabbit spermatozoon incubated with Con A. A uniform layer of reaction product is seen on the plasmalemma. Internal membranes show no reaction. Stained with uranyl and lead salts. $\times 31,500$.

Fig. 4. Flagellum of ejaculated rabbit spermatozoon incubated with Con $A$. The deposit of reaction product is noticeably thinner than on the head. Magnification is the same as for Fig. 3. Stained with uranyl and lead salts. $\times 31,500$.

FIG. 5. Flagellum of capacitated rabbit spermatozoon incubated with Con A. There is marked diminution of reaction product (pointer) on the plasmalemma (arrow). Stained with uranyl and lead salts. $\times 40,500$.

FIG. 6. Gapacitated rabbit spermatozoon incubated with Con A. Reaction product is not seen on the cephalic portion of the plasmalemma (pointer). Stained with uranyl and lead salts. $\times 42,000$. 
the flagellum was markedly reduced (Pl. 1, Fig. 5) and there were large sections of the flagellum which showed no surface coat. When reaction product was present, it was either a very delicate layer, or consisted of small, scattered deposits.

The results demonstrate specific receptors for Con A on the sperm surface indicating the presence of terminal oligosaccharide residues (Bernhard \& Avrameas, 1971) in the glycoprotein cover.

The difference in localization between the head and flagellum support other studies indicating that the surface coating is not uniform over the whole sperm cell, receptors for Con A being more prevalent over the head than the flagellum (Edelman \& Millette, 1971; Nicolson \& Yanagimachi, 1972). Electrophoresis of ejaculated spermatozoa reveals that the tails have a greater net negative charge than the heads (Nevo, Michaeli \& Schindler, 1961; Bedford, 1963). Incubation of spermatozoa with colloidal iron hydroxide at low $\mathrm{pH}$ also revealed a greater concentration of negative charge density over the flagellum (Cooper \& Bedford, 1971; Yanagimachi, Noda, Fujimoto \& Nicolson, 1972). Although the surface coat as demonstrated by binding with Con A was often not continuous over the flagellum, it is unlikely that the plasmalemma is devoid of a glycoprotein cover in these areas. The regions showing no reaction with Con A may contain the moieties that bind colloidal iron. This is supported by the observation that flagella of capacitated spermatozoa have reduced affinity for Con A, but their affinity for colloidal iron is not different from that of ejaculated spermatozoa (Yanagimachi, Nicolson, Noda \& Fujimoto, 1973). It should be emphasized that our methods demonstrate specific carbohydrate components of the surface layer and do not monitor localization of other components.

Our results showed no apparent differences in the topographical localization of Con A receptors on the acrosomal and postacrosomal cap regions of ejaculated spermatozoa, but did demonstrate a change in the binding of Con A to the acrosome of capacitated spermatozoa. This suggests that the surface coat which appears uniform in ejaculated spermatozoa, is in fact constituted differently in these regions.

Loss of Con A binding to the periacrosomal plasmalemma in capacitated spermatozoa provides visible evidence for the removal of glycoproteins, which may be absorbed to ejaculated spermatozoa from the seminal plasma (Kirton \& Hafs, 1965; Hunter \& Nornes, 1969). Attempts to capacitate spermatozoa in vitro by digestion with $\beta$-amylase (Hunter $\&$ Nornes, 1969) or $\beta$-glucuronidase (Gwatkin \& Hutchison, 1971) indicate that some change occurs which shortens fertilization time. Treatment with these enzymes, however, does not fully capacitate spermatozoa (P, V. Dandekar, unpublished observations).

These observations support the hypothesis that capacitation consists of several stages that must be co-ordinated to produce a functional gamete. The factors in the female tract which act on spermatozoa, such as physiological fluids, some derived from the ovarian follicle, cellular elements and lytic enzymes (Soupart, 1972) may produce a change in the physicochemical properties of the plasmalemma. The loss of Con A receptors over the anterior tip of the plasmalemma suggests that an early stage of capacitation may be an alteration, in this region, of the carbohydrate components of the surface layer. This may be followed by 
progressive loss of these moieties from the periacrosomal plasmalemma. If the surface layer is retained on the postacrosomal cap of the fertilizing spermatozoon, it may be significant in view of the fact that hamster and rabbit spermatozoa contact the ovum plasmalemma at this locus (Barros \& Franklin, 1968; Yanagimachi \& Noda, 1970). Presence of the glycoprotein coat, which may have adhesive properties (Dowben, 1969), could promote association of the gamete membranes.

This investigation was supported by Ford Foundation Grant 670-0560 B, and NIH-NICHD-72-2758 contract.

\section{REFERENGES}

Ausrin, G. R. (1964) The capacitation of mammalian spermatozoa. Nature, Lond. 170, 326.

Barros, G., Bedford, J. M., Franklin, L. E. \& Austin, C. R. (1967) Membrane vesiculation as a feature of the mammalian acrosome reaction. 7 . Cell Biol. 34, Gl.

BARRos, G. \& Frankin, L. E. (1968) Behavior of the gamete membranes during sperm entry into the mammalian egg. F. Cell Biol. 37, G13.

BEDFORD, J. M. (1963) Changes in the electrophoretic properties of rabbit spermatozoa during passage through the epididymis. Nature, Lond. 200, 1178.

BERNhARD, W. \& AVRAMEAs, S. (1971) Ultrastructural visualization of cellular carbohydrate components by means of Concanavalin A. Expl Cell Res. 64, 232.

COOPER, G. W. \& BEDFORd, J. M. (1971) Acquisition of surface charge by the plasma membrane of mammalian spermatozoa during epididymal maturation. (Abstract.) Anat. Rec. 169, 300.

DowBen, R. M. (1969) Composition and structure of membranes. In: Biological Membranes, p. 1. Ed. R. M. Dowben. Little, Brown \& Co., Boston.

Dukelow, W. R., Ghernoff, H. N. \& Williams, W. L. (1966) Enzymatic characterization of decapacitation factor. Proc. Soc. exp. Biol. Med. 121, 396.

Dukelow, W. R., Ghernoff, H. N. \& Williams, W. L. (1967) Properties of decapacitation factor and presence in various species. F. Reprod. Fert. 14, 393.

Edelman, G. M. \& Milletre, G. F. (1971) Molecular probes of spermatozoan structure. Proc. nat. Acad. Sci. U.S.A. 68, 2436.

Gwatkin, R. B. L. \& Hutchison, G. F. (1971) Capacitation of hamster spermatozoa by $\beta$-glucuronidase. Nature, Lond. 229, 343.

Hunter, A. G. \& NorNes, H. O. (1969) Characterization and isolation of a sperm-coating antigen from rabbit seminal plasma with capacity to block fertilization. 7. Reprod. Fert. 20, 419.

Johnson, W. L. \& Hunter, A. G. (1972) Seminal antigens: their alteration in the genital tract of female rabbits and during partial in vitro capacitation with beta amylase and beta glucuronidase. Biol. Reprod. 7, 332.

KIRTON, K. T. \& HAFs, H. D. (1965) Sperm capacitation by uterine fluid or $\beta$-amylase in vitro. Science, $\mathcal{N} . r_{.150,618 .}$

Nevo, A. C., Mrchaeli, I. \& Schindler, H. (1961) Electrophoretic properties of bull and rabbit spermatozoa. Expl Cell Res. 23, 69.

Nicolson, G. L. \& YanAGmachi, R. (1972) Terminal saccharides on sperm plasma membranes: identification using specific agglutinins. Science, N.Y. 177, 276.

Soupart, P. (1972) Sperm capacitation: methodology, hormonal control and the search for a mechanism. In: Biology of Mammalian Fertilization and Implantation, p. 54. Eds. K. S. Moghissi and E. S. E. Hafez. C. G. Thomas, Springfield.

Yanagimachi, R., Nicolson, G. L., Noda, Y. D. \& Fujimoto, M. (1973) Electron microscopic observations of the distribution of acidic anionic residues on hamster spermatozoa and eggs before and during fertilization. F. Ultrastruct. Res. 43, 344.

YANAGIMACHI, R. \& NODA, Y. D. (1970) Electron microscope studies of sperm incorporation into the Golden Hamster egg. Am. F. Anat. 128, 429.

Yanagimachi, R., Noda, Y. D., Fujimoto, M. \& Nicolson, G. L. (1972) The distribution of negative surface charges on mammalian spermatozoa. Am. F. Anat. 135, 497. 